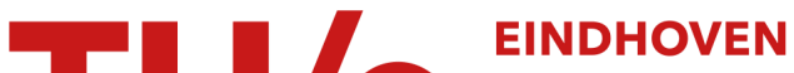 UNIVERSITY OF TECHNOLOGY
}

\section{Electron properties in an atmospheric helium plasma jet determined by Thomson scattering.}

\section{Citation for published version (APA):}

Hübner, S., Sousa, J. S., Puech, V., Kroesen, G. M. W., \& Sadeghi, N. (2014). Electron properties in an atmospheric helium plasma jet determined by Thomson scattering. Journal of Physics D: Applied Physics, 47(43), 432001-1/6. https://doi.org/10.1088/0022-3727/47/43/432001

DOI:

10.1088/0022-3727/47/43/432001

Document status and date:

Published: 01/01/2014

\section{Document Version:}

Publisher's PDF, also known as Version of Record (includes final page, issue and volume numbers)

\section{Please check the document version of this publication:}

- A submitted manuscript is the version of the article upon submission and before peer-review. There can be important differences between the submitted version and the official published version of record. People interested in the research are advised to contact the author for the final version of the publication, or visit the $\mathrm{DOI}$ to the publisher's website.

- The final author version and the galley proof are versions of the publication after peer review.

- The final published version features the final layout of the paper including the volume, issue and page numbers.

Link to publication

\section{General rights}

Copyright and moral rights for the publications made accessible in the public portal are retained by the authors and/or other copyright owners and it is a condition of accessing publications that users recognise and abide by the legal requirements associated with these rights.

- Users may download and print one copy of any publication from the public portal for the purpose of private study or research.

- You may not further distribute the material or use it for any profit-making activity or commercial gain

- You may freely distribute the URL identifying the publication in the public portal.

If the publication is distributed under the terms of Article $25 \mathrm{fa}$ of the Dutch Copyright Act, indicated by the "Taverne" license above, please follow below link for the End User Agreement:

www.tue.nl/taverne

\section{Take down policy}

If you believe that this document breaches copyright please contact us at:

openaccess@tue.nl

providing details and we will investigate your claim. 
Electron properties in an atmospheric helium plasma jet determined by Thomson scattering

This content has been downloaded from IOPscience. Please scroll down to see the full text.

2014 J. Phys. D: Appl. Phys. 47432001

(http://iopscience.iop.org/0022-3727/47/43/432001)

View the table of contents for this issue, or go to the journal homepage for more

Download details:

IP Address: 131.155.151.148

This content was downloaded on 22/12/2014 at 08:04

Please note that terms and conditions apply. 


\title{
Electron properties in an atmospheric helium plasma jet determined by Thomson scattering
}

\author{
S Hübner ${ }^{1,4}$, J Santos Sousa ${ }^{2}$, V Puech ${ }^{2}$, G M W Kroesen ${ }^{1}$ and N Sadeghi ${ }^{3}$ \\ ${ }^{1}$ Department of Applied Physics, Eindhoven University of Technology, PO Box 513, 5600 MB \\ Eindhoven, The Netherlands \\ ${ }^{2}$ LPGP, CNRS \& Université de Paris-Sud, 91405 Orsay, France \\ 3 LIPhy, (UMR 5588) \& LTM (UMR 5129), Université de Grenoble \& CNRS, Grenoble F-38402, France \\ ${ }^{4}$ Present address: Reactive Plasmas \& EP2, Ruhr-Universität Bochum, 44780 Bochum, Germany \\ E-mail: simon.huebner.physik@gmail.com and joao.santos-sousa@u-psud.fr
}

Received 2 July 2014, revised 27 August 2014

Accepted for publication 8 September 2014

Published 6 October 2014

\begin{abstract}
In this work we present Thomson scattering measurements on a nanosecond pulsed high voltage dielectric barrier discharge (DBD)-like helium plasma jet, operated in ambient air. With the low detection limit offered by a triple grating spectrograph equipped with a high quantum efficiency intensified charge-coupled device (ICCD) camera, temporally and spatially resolved electron densities and mean energies have been mapped. $7 \mathrm{kV}$ peak with $250 \mathrm{~ns}$ width pulses at $20 \mathrm{kHz}$ are applied to the inner cylindrical shaped electrode of a DBD. This results in a peculiar hollow electron density profile in the vicinity of the jet nozzle with maximum values of $n_{\mathrm{e}}=5 \times 10^{18} \mathrm{~m}^{-3}$ and mean energies of up to $2.5 \mathrm{eV}$. Further downstream, the profile collapses radially and contracts. A much higher electron density is found $\left(2 \times 10^{19} \mathrm{~m}^{-3}\right)$ while the mean energy is lower $(0.5 \mathrm{eV})$.
\end{abstract}

Keywords: electron density and energy, pulsed plasma jet, Thomson scattering, non-thermal, helium

(Some figures may appear in colour only in the online journal)

In recent years, atmospheric pressure microplasma jets have attracted much interest because of the possibility of propagating non-thermal plasmas in open air (Lu et al 2012). As so, reactive plasma species (e.g. radicals, ions, UV radiation), and not only long-living afterglow species, can be delivered, at ambient pressure and temperature, to targets located some centimeters away from the main discharge zone. This property enables the development of a wide range of new and promising applications, e.g. in biomedicine and healthcare. Despite enormous potential for technological applications, the fundamentals of microplasma jets are not yet fully understood. As electrons play an important role in the physical and chemical properties of plasmas, it is thus very important to study and quantify the plasma electron properties (density and temperature) for the development and optimization of microplasma jet sources. In this paper, we present the first spatially and temporally resolved direct measurements of electron density and temperature in a helium microplasma jet. So far, almost all experimental results that have been published on the electrons properties of atmospheric pressure microplasma jets were determined by Stark broadening (Qian et al 2010, Hofmann et al 2011, Xiong et al 2013) or estimated from current measurements (Chichina et al 2005, Hao et al 2012, Karakas et al 2012, Begum et al 2013, Gazeli et al 2013). Despite those plasma jets having similar characteristics with respect to the velocity and propagation length, the electron densities found, spanned puzzlingly from a few $10^{16} \mathrm{~m}^{-3}$ up to several $10^{21} \mathrm{~m}^{-3}$. It is also worth to notice that while the 
electron densities determined from Stark broadening of hydrogen lines were always higher than several $10^{19} \mathrm{~m}^{-3}$, those estimated from current measurements were always lower than a few $10^{18} \mathrm{~m}^{-3}$. The different geometry has certainly an influence on the true value, for instance the position and distance of the electrodes determines strongly the current density in the plasma. However, even for the same jet, differences of an order of magnitude are found (Hofmann et al 2011). Actually, we have also obtained such incongruous results in our microplasma jet. The estimated electron density was several $10^{19} \mathrm{~m}^{-3}$ by Stark broadening and up to few $10^{18} \mathrm{~m}^{-3}$ from current measurements (Douat 2013).

In fact, both methods suffer from the indirect determination of the electron density and from volume averaging effects. More precisely, the different issues concerning the Stark broadening of the hydrogen emission lines are (1) the width of hydrogen lines characterize the surrounding of the emitting atom, which, a priori, is not correlated to the plasma density. This is particularly the case when $\mathrm{H}$ atoms from incoming air are produced in the periphery of the plasma by ion-ion or electron-ion recombination (Verreycken 2012); (2) emission spectroscopy measurements rely on line of sight observation of the plasma emission. When dealing with an inhomogeneous medium, as it is the case for the microplasma jet, the recorded line profile results from the addition of an infinite number of different line profiles, and complicated inversion processing of the data, with often not always justified hypothesis, is necessary for the determination of the local Stark widths; (3) due to the atmospheric pressure operation of these jets, the van der Waals broadening is often comparable, if not larger than the Stark broadening. Thus, the accuracy of the electron density deduced from the Stark width strongly depends on the accurate knowledge of the gas temperature, $T_{\mathrm{g}}$. In fact, $T_{\mathrm{g}}$ influences both the Doppler and van der Waals width of the Voigt profile of the line. Consequently, its independent determination is necessary (Belostotskiy et al 2010); (4) As was specified by Gigosos et al (2003), the Hamiltonian of $\mathrm{H}$ atoms used by these authors to develop the Stark model for the Balmer series does not include the fine structure effect, and only permit to correlate correctly the line width to the electron density when it is higher than about $1 \times 10^{20} \mathrm{~m}^{-3}$. As so, in our opinion, electron densities resulting from Stark width measurements that have been so far published for He plasma jet cannot be considered to be fully reliable. The electron density determination based on current measurements has also several drawbacks. On one hand, the current probe can be intrusive and may change the characteristics of the plasma jet. Thus, a correct determination of the plasma jet current is rather challenging. On the other hand, even if the plasma jet current is well determined, one has to estimate the electron velocity, the plasma jet diameter, and the radial shape of the electron distribution. Similar difficulties occur in other methods used to determine the electron density. Microwave scattering and laser interferometry (Choi et al 2009, Shashurin et al 2010) generate always volume or line of sight averaged data.
Therefore, in order to obtain reliable values for the electron properties of our microplasma jet, we have used the Thomson scattering technique which is free from the above mentioned artifacts. Moreover, this method provides high spatially $(100 \mu \mathrm{m})$ and temporally (2ns) resolved measurements of the electron density and temperature, with negligible perturbation of the plasma. Finally, similar to the published experimental data, the numerical models that can be found in the literature also propose contradictory values and trends for the electron density of helium microplasma jets propagating in ambient air (Breden et al 2012, Naidis 2012, Boeuf et al 2013). It is thus the aim of this work to clarify that issue and help to improve the numerical models that can play a crucial role in fully analyzing and understanding the physics and the chemistry behind such microplasma jets.

The device used in this work is basically the same as the one described in (Douat et al 2011). It consists of a quartz tube (inner diameter $2.1 \mathrm{~mm}$, outer diameter $7.1 \mathrm{~mm}$ ) with a coaxial inner capillary high voltage (HV) electrode that is glued inside at a distance of $7 \mathrm{~mm}$ from the tip. A $1 \mathrm{~cm}$ wide grounded electrode ring is wrapped around the dielectric tube at a distance of $5 \mathrm{~mm}$ from its tip. Helium gas flow of $4.5 \mathrm{slm}$ goes directly through the capillary electrode and emanates into open air. The whole setup is mounted on an $x-y$ stepper-motor stage. The discharge is driven at $20 \mathrm{kHz}$ by high voltage pulses produced by a homemade power supply. The rise time of the $7 \mathrm{kV}$ peak $\mathrm{HV}$ pulses is $150 \mathrm{~ns}$ and their duration at half maximum is about $250 \mathrm{~ns}$.

We use a second harmonic Nd:YAG laser at $532 \mathrm{~nm}$ with a repetition frequency of $5 \mathrm{kHz}$, a pulse width (FWHM) of $8 \mathrm{~ns}$ and a pulse energy of $4 \mathrm{~mJ}$. A $1 \mathrm{~m}$ focal length lens is mounted on a moveable stage and provides a smaller than $100 \mu \mathrm{m}$ laser beam diameter at the jet. Because of the small focal spot, low pulse energies are needed in order to prevent plasma perturbations by the laser.

The scattered photons are detected under $90^{\circ}$ by a triple grating spectrograph equipped with an intensified chargecoupled device (ICCD) camera (van de Sande and van der Mullen 2002). HV and laser pulses and the gate of the ICCD are synchronized relative to each other. A 2D image is obtained, one axis corresponding to the spatial dimension along the laser beam and the other axis resolving the spectral information. The spatial resolution depends not only on the laser beam diameter and the enlargement factor of the imaging but also on the noise level of the detected signal, which demands a spatial binning of the CCD pixels, leading to at least $100 \mu \mathrm{m}$. The detected scattered photon signal intensity is proportional to the electron density, while the spectral distribution is related to the electron energy distribution function (EEDF). To obtain absolute values in wavelength and amplitude, a calibration of the signal is provided by Raman spectra of ambient air by fitting the $\mathrm{N}_{2}$ and $\mathrm{O}_{2}$ rotational peaks (Van Gessel et al 2012). With this system, electron densities as low as $5 \times 10^{17} \mathrm{~m}^{-3}$ and electrons with energies in the range of $0.1-8 \mathrm{eV}$ can be detected. Note, however, that the upper energy limit depends strongly on the electron density, as will be shown later.

The standard experimental procedure involves taking three spectra that are accumulated over $1.5 \times 10^{6}$ laser shots 


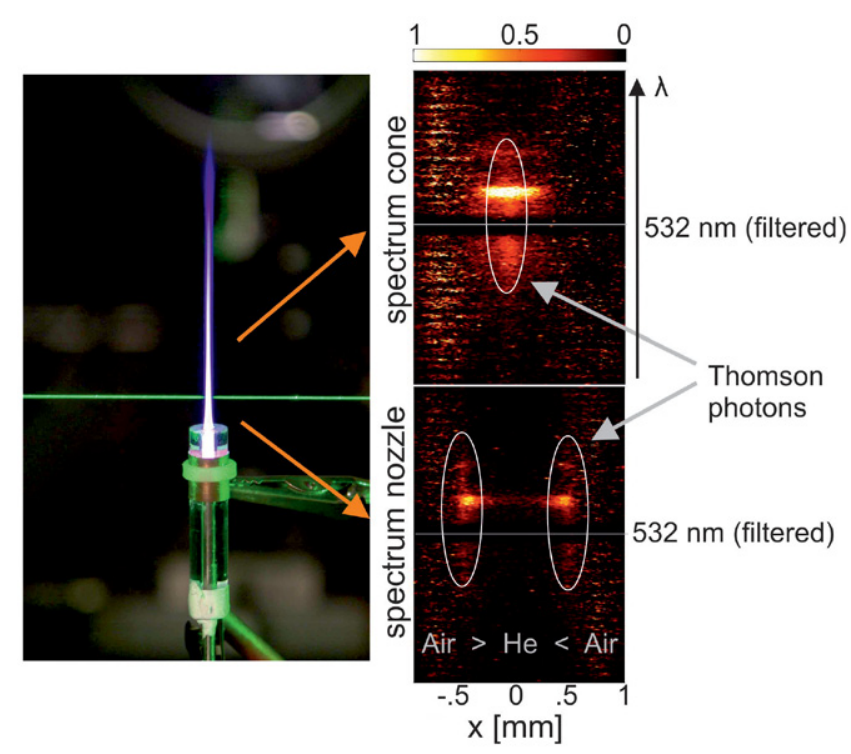

Figure 1. Photograph of the jet operating with a He flow and crossing laser beam. Shown are also two representative laser scattering spectra from different axial positions (top: $z=11 \mathrm{~mm}$; bottom: $z=2 \mathrm{~mm}$ ). The wavelength scale is roughly from 528 to $536 \mathrm{~nm}$ ( $\pm 4 \mathrm{~nm}$ from the laser). The scattered photons with a Gaussian distribution around the laser wavelength are the TS signal. Not fully suppressed Raman scattering at the edges of the jet and a strong plasma emission found at about $533 \mathrm{~nm}$ can also be seen.

(300s) each, one to record the laser scattered photons with plasma ON, one to record the laser stray light and Raman scattered photons without plasma, and one to record only the plasma emission. In the recorded spectral range, the latter mainly contains the $\mathrm{N}_{2}{ }^{+} \mathrm{B}^{2} \Sigma \rightarrow \mathrm{X}^{2} \Sigma$ transition of nitrogen, produced by Penning ionization of $\mathrm{N}_{2}$ by helium metastable atoms. However, we observe that the intensity of the nitrogen bands is much higher when the laser is on, pointing to a possible laser induced fluorescence phenomenon. Indeed, the rotational $\mathrm{Q}(1-1)$ line of the $\mathrm{N}_{2}^{+} \mathrm{B}\left(v^{\prime}=8\right) \rightarrow$ $\mathrm{X}\left(v^{\prime \prime}=12\right)$ transition is very close to the position of the laser wavelength. We remark that the radial profile of this extra emission, hollow shape at the exit of the tube and centred downstream $(z>9 \mathrm{~mm})$, is similar to the profile of $\mathrm{He}^{\mathrm{M}}$ metastable atoms obtained by laser absorption spectroscopy (Cadot et al 2014).

A photograph of the jet in operation is given in figure 1 along with two spectra of the scattered laser photons corrected for the plasma emission. The strong Raman scattering of the laser beam on the surrounding air is also subtracted but leaves noisy traces on the radial edges of the spectra. At $z=2 \mathrm{~mm}$, a spectrally Gaussian distributed signal is found around the laser wavelength at two outer radial positions, while at $z=11 \mathrm{~mm}$ the Thomson laser scattering spectra only occurs around the center. In the central He flow, one can see the aforementioned laser induced fluorescence at about $533 \mathrm{~nm}$.

At different positions $z$ along the jet axis, the guided streamer arrives at different delay times corresponding to its velocity of about $180 \mathrm{~km} \mathrm{~s}^{-1}$. This temporal evolution is shown in figure 2. At $z=2 \mathrm{~mm}, 11 \mathrm{~mm}, 22 \mathrm{~mm}$, the maximum plasma emission was detected at $80 \mathrm{~ns}, 135 \mathrm{~ns}$ and $195 \mathrm{~ns}$ respectively. The time evolution is as follows: close to the electrode $(z=2 \mathrm{~mm})$ we find the highest mean electron energy of up to $2.5 \mathrm{eV}$ and for all positions the mean energy decays in time due to the electronic collisions taking place after the passage of the ionization wave that reduces the energy per electron. Note that the mean energy is given as $\langle E\rangle=3 / 2 k T_{\mathrm{e}}$, where $T_{\mathrm{e}}$ is deduced from the Gaussian fit of the TS spectra. The electron density reaches values between $5 \times 10^{18}$ and $1.5 \times 10^{19} \mathrm{~m}^{-3}$, depending on the axial and radial positions. At $z=2 \mathrm{~mm}$, densities are for the radial rim of the jet but further downstream they are for the jet axis. The spatial distribution will be discussed later on. The electron density shows only little variation during the (current) pulse and drops steeply at its termination. That is in contrast to (Huebner et al 2013) where in an argon needle-jet configuration without second electrode a steep decrease of $n_{\mathrm{e}}$ after an initial maximum was found. Note that the density and energy values are averaged over the laser beam diameter and over the laser pulse duration (8ns), so that locally and temporally higher maxima might occur. However, the temporal and spatial averaging should not affect significantly either the temporal or spatial evolution of the mean energy and the electron density, nor their values shown in this paper.

We assume that in our case an initial electron energy maximum, or ionization front, is present but the $S / N$ level of the TS signal is too low to permit the detection. As seen in figure 3 , only the energy range $0.1-2 \mathrm{eV}$ of the measured EEDF, corresponding to the bulk electrons, can be exploited for the mean energy determination. Consequently, the density of high energy electrons of the streamer head remains below the detection limit.

The radial profiles of the electron density and energy for different axial positions at a fixed time delay of $120 \mathrm{~ns}$ with respect to the plasma emission are shown in figure 4 . The evolution shows a transition from a hollow plasma tube for $z<9 \mathrm{~mm}$ to a centred channel and subsequently to an again broader, if not slightly hollow, profile for $z>13 \mathrm{~mm}$. For $z>29 \mathrm{~mm}$, the broader channel is decaying and the air entrainment creates a Raman signal that becomes too strong and overlaps the TS signal. At $z=2 \mathrm{~mm}$, the electron density in the center is below the detection limit. The slight asymmetry in the results is due to a horizontal gas flow in the jet (note that $r=0$ is taken in respect to the tube, not the plasma). A rotation of 180 degrees of the tube and its electrodes flips the results radially. As a matter of fact, a similar asymmetry can be found in the plasma emission intensity, originating mostly from $\mathrm{He}$ and $\mathrm{N}_{2}^{+}(\mathrm{B})$, as shown in figure 5 .

To summarize, in this paper we showed the first spatially and temporally resolved direct measurements of electron density and mean energy in a helium microplasma jet. In order to obtain reliable values for the electron properties of our microplasma jet, we used the Thomson scattering technique. We found that the profile of the electron density along the $z$-axis generally evolves from hollow to axially centred. In the vicinity of the electrode the plasma retains the hollow shape of the HV electrode in the He channel. As the necessary breakdown field in the ambient air is higher than in He, the discharge remains confined inside the jet. This general trend was found already for the spatial distribution of the plasma light emission (Algwari and O'Connell 2011) and the density 


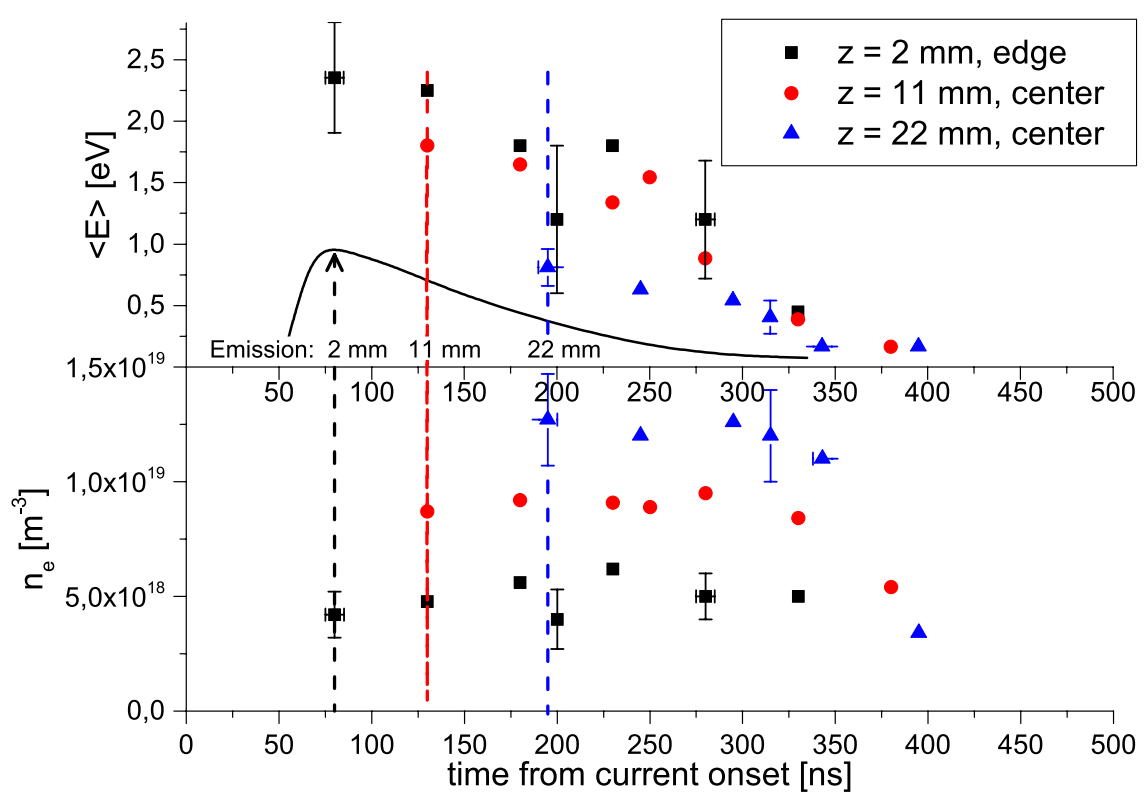

Figure 2. Temporal evolution of the electron parameters at three different axial positions. For $z=2 \mathrm{~mm}$ the visible plasma emission intensity in arbitrary units is shown as full curve, while dashed lines indicate the time of the respective maxima. After about $400 \mathrm{~ns}$ the current goes to zero.

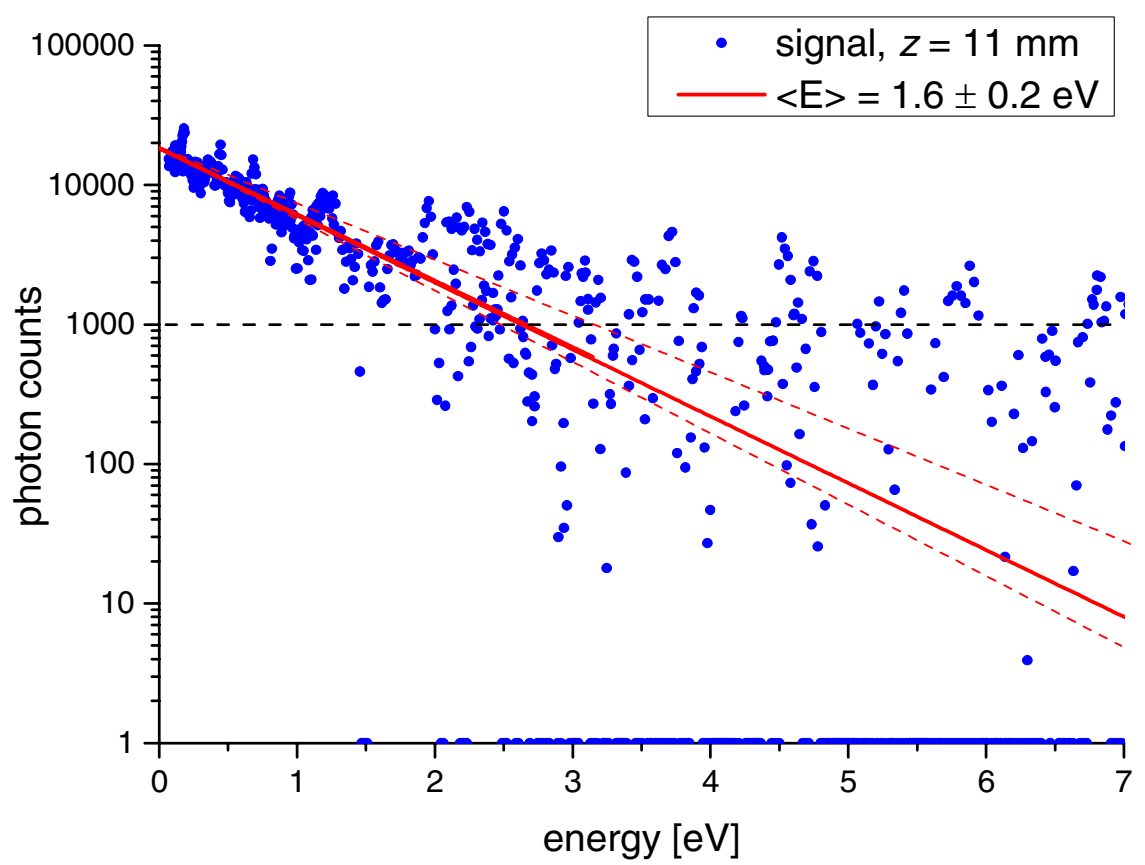

Figure 3. EEDF from Thomson scattered photon spectra for $n_{\mathrm{e}}=8 \times 10^{18} \mathrm{~m}^{-3}(z=11 \mathrm{~mm}$ and time span between the detection of plasma emission and measurement of $100 \mathrm{~ns}$ ). A Gaussian fit for the electron energy with a single standard deviation interval is shown. The horizontal dashed line indicates the noise level. Note that negative values are plotted as one.

of He atoms in metastable states (Urabe et al 2010). Choi et al (2009) also observed by laser heterodyne interferometry a hollow electron density profile collapsing to axially centred along the $z$-axis in a pulsed DC jet. But, contrary to us, they found the electron density decreasing as the jet propagates. However, their jet is operated in an inverted polarity and their electrode configuration is quite different from ours (facing electrodes).

While our measurements agree quite well with most of the published models (Naidis 2011, Breden et al 2012) with respect to the general evolution of the radial distribution of the electron density, with a shape progressively evolving from an annular distribution to a closed one on-axis centred (note that the different models propose different values and axial collapsing points of the electron density), it must be pointed out that our measurements clearly indicate that the maximum electron density is reached after a propagation of several $\mathrm{cm}$. This trend strongly disagrees with the prediction of almost all models (Breden et al 2012, Boeuf et al 2013) in which the electron density has its maximum value just at the tip of the dielectric tube and progressively decreases 


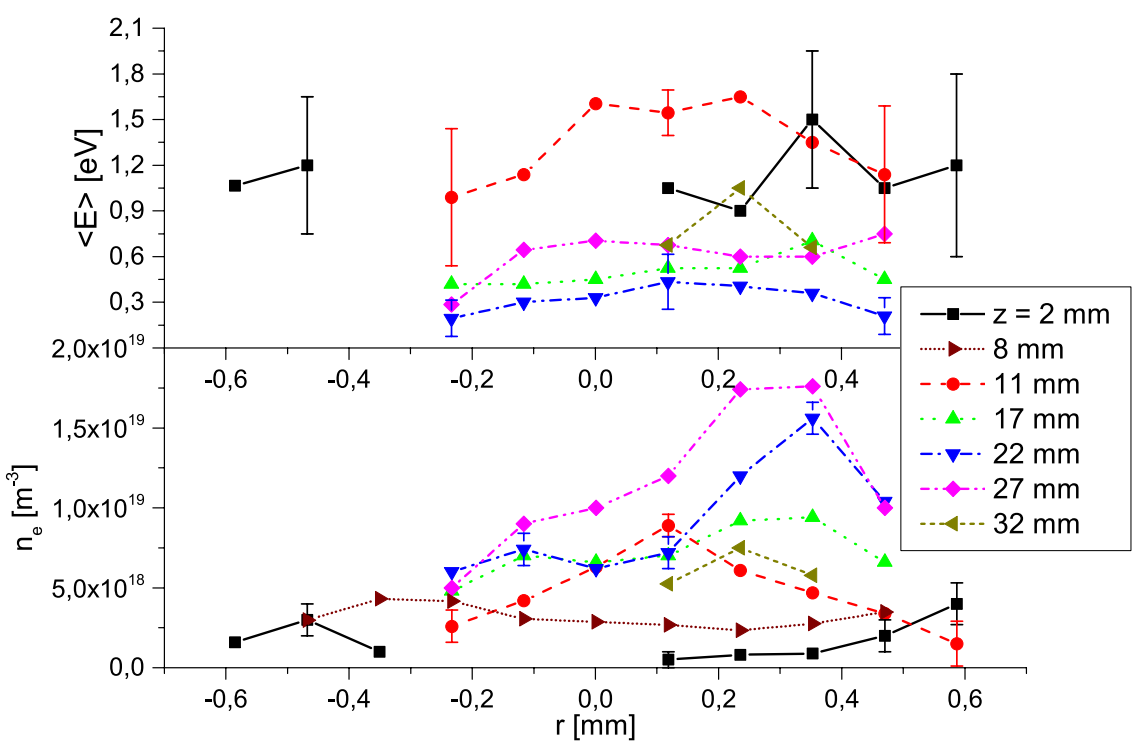

Figure 4. Spatial evolution of electron mean energy (top) and density (bottom) as a function of the axial position for a $120 \mathrm{~ns}$ fixed time span between the detection of plasma emission and measurements.

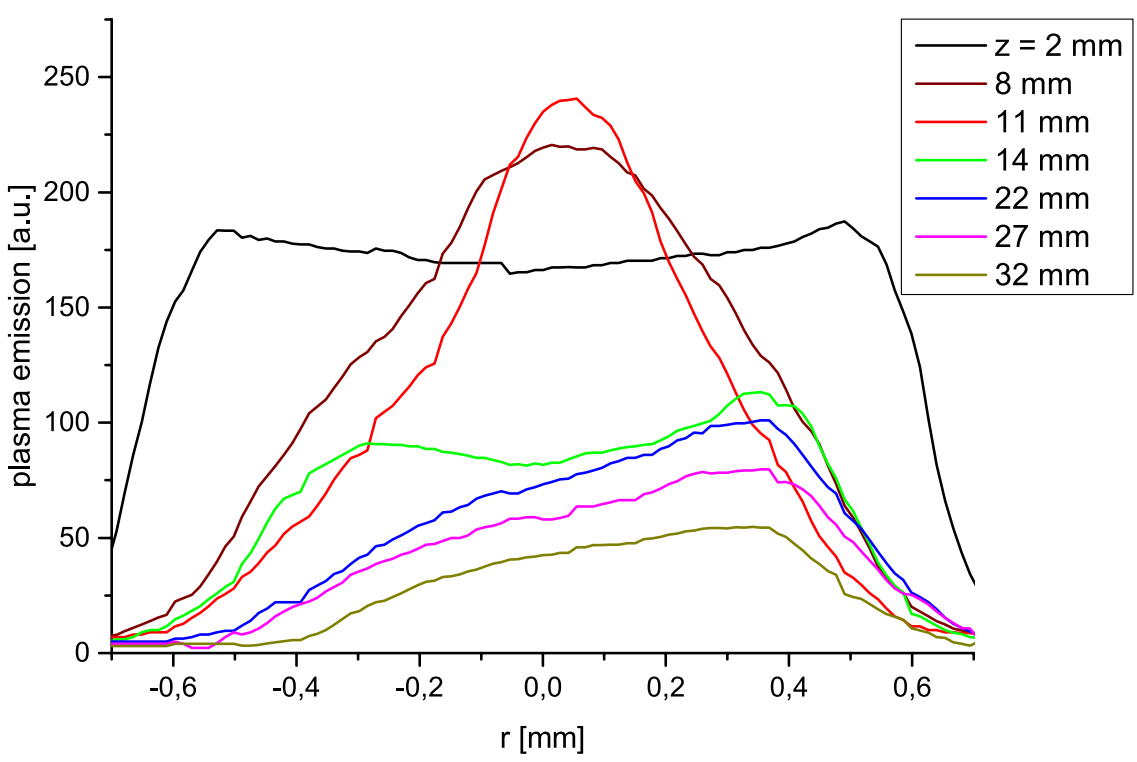

Figure 5. Lateral plasma emission profiles in arbitrary units for different axial positions. The emission is line of sight integrated.

as the plasma jet propagates. The best agreement between model and our experiment, not only in plasma shape but also in absolute electron density, can be found with the work of Naidis (2012).

It is worth mentioning that the measured trend for the longitudinal distribution of the electron density is in agreement with the recent measurements of the distribution of helium atoms in the metastable state by Cadot et al (2014) who found, for the same device, a maximum density of the $\mathrm{He}\left(2^{3} \mathrm{~S}\right)$ atoms $13 \mathrm{~mm}$ downstream the dielectric tip, while here again models predict a maximum metastable density just at the tip. Such differences are still unresolved, and perhaps the measured axial distribution of the metastable and electron densities and of the electron temperature can now be used to improve the accuracy of the model predictions, and, ultimately, lead to a better understanding of the physics and chemistry behind the microplasma jets.

\section{Acknowledgments}

This work is supported by the French 'Agence Nationale de la Recherche' through the project 'PAMPA' (Grant No ANR-2010- BLAN-0930-01).

\section{References}

Algwari Q Th and O'Connell D 2011 Electron dynamics and plasma jet formation in a helium atmospheric pressure dielectric barrier discharge jet Appl. Phys. Lett. 99121501 
Begum A, Laroussi M and Pervez M R 2013 Atmospheric pressure He-air plasma jet: Breakdown process and propagation phenomenon AIP Adv. 3062117

Belostotskiy S G, Ouk T, Donnelly V M, Economou D J and Sadeghi N 2010 J. Appl. Phys. 107053305

Boeuf J-P, Yang L L and Pitchford L C 2013 Dynamics of a guided streamer (plasma bullet) in a helium jet in air at atmospheric pressure J. Phys. D: Appl. Phys. 46015201

Breden D, Miki K and Raja L L 2012 Self-consistent 2D modeling of cold atmospheric-pressure plasma jets/bullets Plasma Sources Sci. Technol. 21034011

Cadot G, Douat C, Puech V and Sadeghi N 2014 Spatio-temporally resolved mapping of helium metastable density in an atmospheric pressure plasma jet IEEE Trans. Plasma Sci. in press (doi: 10.1209/TPS.2014.2310231)

Chichina M, Hubicka Z, Churpita O and Tichy M 2005 Measurement of the parameters of atmospheric-pressure barrier-torch discharge Plasma Process. Polym. 2 501-6

Choi J-Y, Takano N, Urabe K and Tachibana K 2009 Measurement of electron density in atmospheric pressure small-scale plasmas using $\mathrm{CO}_{2}$-laser heterodyne interferometry Plasma Sources Sci. Technol. 18035013

Douat C 2014 Étude d'un micro-jet de plasma à pression atmosphérique $P h D$ Thesis Université Paris-Sud, France

Douat C, Bauville G, Fleury M, Laroussi M and Puech V 2012 Dynamics of colliding microplasma jets Plasma Sources Sci. Technol. 21034010

Gazeli K, Svarnas P, Vafeas P, Papadopoulos P K, Gkelios A and Clément F 2013 Investigation on streamers propagating into a helium jet in air at atmospheric pressure: electrical and optical emission analysis J. Appl. Phys. 114103304

Gigosos M A, Gonzalez M A and Cardenoso V 2003 Computer simulated Balmer-alpha, -beta and -gamma Stark line profiles for non-equilibrium plasmas diagnostics Spectrochim. Acta B 581489

Hao Z, Ji S and Qiu A 2012 Study on the influence of dielectric barrier materials on the characteristics of atmospheric plasma jet in Ar IEEE Trans. Plasma Sci. 402822

Hofmann S,van Gessel A F H, Verreycken T and Bruggeman P 2011 Power dissipation, gas temperatures and electron densities of cold atmospheric pressure helium and argon RF plasma jets Plasma Sources Sci. Technol. 20065010

Hübner S, Hofmann S, van Veldhuizen E M and Bruggeman P J 2013 Electron densities and energies of a guided argon streamer in argon and air environments Plasma Sources Sci. Technol. 22065011

Karakas E, Akman M A and Laroussi M 2012 The evolution of atmospheric-pressure low-temperature plasma jets: jet current measurements Plasma Sources Sci. Technol. 21034016

Lu M, Laroussi M and Puech V 2012 On atmospheric-pressure nonequilibrium plasma jets and plasma bullets Plasma Sources Sci. Technol. 21034005

Naidis G V 2011 Simulation of streamers propagating along helium jets in ambient air: polarity induced effects Appl. Phys. Lett. 98141501

Naidis G V 2012 Modeling of helium plasma jets emerged into ambient air: influence of applied voltage, jet radius, and helium flow velocity on plasma jet characteristics, J. Appl. Phys. 112103304

Qian M, Ren C, Wang D, Zhang J and Wie G 2010 Stark broadening measurement of the electron density in an atmospheric pressure argon plasma jet with double-power electrodes J. Appl. Phys. 107063303

Shashurin A, Shneider M N, Dogariu A, Miles R B and Keidar M 2010 Temporary-resolved measurement of electron density in small atmospheric plasmas Appl. Phys. Lett. 96171502

Urabe K, Morita T, Tachibana K and Ganguly B N 2010 Investigation of discharge mechanisms in helium plasma jet at atmospheric pressure by laser spectroscopic measurements J. Phys. D: Appl. Phys. $\mathbf{4 3} 095201$

van de Sande M J and van der Mullen J J A M 2002 Thomson scattering on a low-pressure, inductively-coupled gas discharge lamp J. Phys. D: Appl. Phys. 351381

van Gessel A F H, Carbone E A D, Bruggeman P J and van der Mullen J J A M 2012 Laser scattering on an atmospheric pressure plasma jet: disentangling Rayleigh, Raman and Thomson scattering Plasma Sources Sci. Technol. 21015003

Verreycken T, Sadeghi N and Bruggeman P J 2014 Time-resolved absolute $\mathrm{OH}$ density of a nanosecond pulsed discharge in atmospheric pressure $\mathrm{He}-\mathrm{H}_{2} \mathrm{O}$ : absolute calibration, collisional quenching and the importance of charged species in $\mathrm{OH}$ production Plasma Sources Sci. Technol. 23045005

Xiong Q, Yu Nikiforov A, Gonzalez M A, Leys C and Lu X P 2013 Characterization of an atmospheric helium plasma jet by relative and absolute optical emission spectroscopy Plasma Sources Sci. Technol. 22015011 